\title{
Spinous injury caused by a sea urchin
}

\author{
L J McWilliam, A Curry, P L Rowland, J S Watson
}

\begin{abstract}
A bather on holiday in Kenya injured a finger on a spiny marine creature living on the sea bed. A skin biopsy specimen from the injured finger contained several black spines about $0.5 \mathrm{~mm}$ in diameter and up to $1.5 \mathrm{~cm}$ in length. Spines removed from the specimen were embedded in plastic resin to facilitate transverse sectioning. Light microscopical examination using crossed polarisers showed an ornate symmetrical structure brightly illuminated against a dark background. These features are characteristic of sea urchin (Echinoderm) spines which are composed of ornately formed calcite crystals covered by an epithelium. The spines of sea mice, on the other hand, are chitinous in nature; they are also much finer and lack the ornate symmetry of sea urchin spines.
\end{abstract}

\section{Case report}

Injury from sea urchin spines is a well recognised hazard for bathers, particularly in the Mediterranean. We recently reported a case of spinous injury due to a sea mouse annelid worm $^{1}$ and have subsequently received a skin biopsy specimen containing spines from a genuine sea urchin (Echinoderm) injury. This injury was sustained while bathing in Kenya.

\section{Methods and Results}

The skin biopsy specimen comprised epidermis and dermis containing several black spines about $0.5 \mathrm{~mm}$ in diameter and of variable length up to $1.5 \mathrm{~cm}$. Spinous material was present in tissue which had been conventionally embedded in paraffin wax for routine haematoxylin and eosin staining. The spines tended to protrude from the specimen because of their calcific nature. The epidermis contained microabscesses but there was no evidence of a granulomatous response in the dermis.

Other spines removed from the tissue were dehydrated and orientated to facilitate transverse sectioning in the specimen moulds before resin embedding. The resin used was Agar 100 resin (Agar Scientific). Transverse sections ( $1 \mu \mathrm{m}$ thick) were cut and stained with toluidine blue. The ornate symmetrical structure of the spines was poorly visualised in the stained sections, but using polarised light the birefringent nature of the calcite within the spines stood out brightly against a dark background (figure).

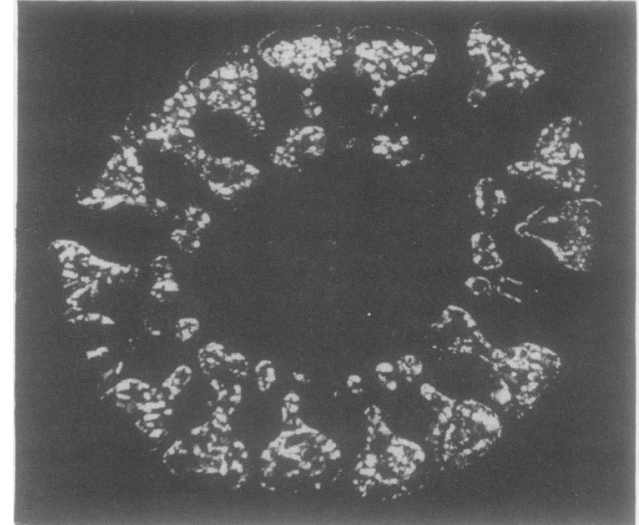

Symmetrical and highly ornate cross-sectional structure of sea urchin spine viewed under polarised light.

\section{Discussion}

Sea urchins are probably the most well known of all spiny marine organisms and it is therefore not surprising that injuries caused by these organisms are reported most often. Their spines consist of one or several elongated calcium carbonate (calcite) crystals covered by an epithelial layer. ${ }^{23}$ Some are hollow; others are solid. In cross-section they are symmetrical and highly ornate with a diameter of up of $2 \mathrm{~mm}$. They are best shown in resin embedded, semithin transverse sections viewed under polarised light. In contrast, sea mice spines are not composed of an optically active mineral such as calcite but are chitinous in nature. ${ }^{1}$ They are also much finer and lack the ornate symmetry of sea urchin spines.

Injuries due to various spiny plant and animal species can evoke both local and systemic reactions, ${ }^{4}$ and the local reaction is sometimes of a granulomatous sarcoidal type. $^{145}$ This case showed only a local acute inflammatory reaction with microabscess formation in contrast to our previously reported case $^{1}$ in which destructive granulomatous arthritis necessitated digit amputation.

Spines are commonly found in the animal and plant kingdom, and all have their own characteristic structure, morphology, and composition. Examination of any spines found in tissue injuries should help to identify the organism involved and further our knowledge of these increasingly common injuries.

1 Wilson GE, Curry A, Kennaugh JH, McWilliam LJ, Watson JS. Severe granulomatous arthritis due to spinous injury by a "sea mouse" annelid worm. J Clin Pathol 1990;43:291-4.

2 Baden HP. Injuries from sea urchins. Clin Dermatol 1987;5:112-17.

3 Nichols D. Echinoderms. 4th ed. London: Century Hutchinson, 1969:96-7.

4 Cracchiolo A, Goldberg L. Local and systemic reactions to puncture injuries by the sea urchin spine and the date palm thorn. Arthritis Rheum 1977;20:1206-12.

5 Cooper P, Wakefield MC. A sarcoid reaction to injury by sea urchin spines. J Pathol 1974;112:33-6. 